\title{
Time and habitat heterogeneity constrain the opportunity for sexual selection during mating
}

The growing interest in the mechanisms of sexual selection has produced a proliferation of hypotheses on mate choice showing that the problem is very complex and that it involves many variables (Janetos 1980, Andersson 1994, Gibson \& LANGEn 1996). These observations give us cause to reassess our generalisations on the rules and opportunity for sexual selection (Cunningham \& Birkhead 1998, Gontard-Danek \& Møller 1999). Parker (1983) and HubBell \& Johnson (1987) have already predicted that the pattern of mating could be random, if the variation among males in secondary sexual traits is small and the time available for pairing is short. Moreover, life-history strategies, the evolution of alternative reproductive tactics and the occurrence of some constraints (e.g. searching costs, competition, time, predation, mate density and distribution) can lower the opportunity for sexual selection (e.g., ECKERT \& WeAtherheAd 1987, BJÖRKLUnd 1990, MCLAin 1991, Shutler \& Weatherhead 1991, Slagsvold \& Dale 1991, Winemiller 1992, Sullivan 1994, Neff 2001). We can hypothesise that, under several natural scenarios, some constraints could prevent sexual selection from affecting the process of pair formation. Here, we propose a new constraint associated with habitat heterogeneity. When there is considerable variation in territory quality due to habitat heterogeneity, the increasing risk of losing the territory by being chased away by a usurper (BLACK 1996) might represent a major constraint on time to choose a mate. Alternative mating tactics evolved under this scenario may differ from those evolved by sexual selection alone. Variation in the suitability of territories probably exists to some degree in most if not all animal populations, and recently RoDENHOUsE et al. $(1997,1999)$ introduced the concept of site-dependent species, in which individual fitness depends on exclusive use of a territory. The spatial distribution of resources is considered one of the most important influences on behavioural variation (EMLEN \& ORING 1977), and was shown to affect the degree of sexual selection within a population (MARsh et al. 2000, Ferrer \& Penteriani 2003). In birds, the importance of territory quality as a selective force potentially shaping mating systems is generally supported by two observations (e.g., SEARCy 1979, ENs et al. 1996, Newton \& Wyllie 1996, Russel \& Rowley 1996). First, many individuals select the characteristics of breeding sites, not those of the potential partners occupying such sites. Second, mate fidelity can be a by-product of nest site fidelity, as a result of accepting a vacancy in an established territory in which a bird of the opposite sex is already present. Many territorial species despotically and pre-emptively occupy sites that differ in suitability for reproduction and/or survival, thus relegating other individuals to lower-quality sites. For these species, a mating strategy based on maximising the probability of choosing the best available mate may not be profitable. One animal group that exemplifies the despotic territoriality model is raptors. Birds of prey are a site-dependent species group in which manifest morphological secondary sexual traits permitting an easy and fast evaluation of individual quality do not always seem well developed. Several cases of rapid mating, suggesting temporal constraints for sexual selection opportunities, are reported by NewTon (1979) and BowMAN \& BIRD (1987): African Red-tailed Buzzards Buteo auguralis, American Kestrels Falco sparverius, Eurasian Kestrels Falco tinnunculus, Peregrines Falco peregrinus and Swainson's Hawks Buteo swainsoni were observed mating within just one day. In these cases, replacing occurred within such a short time that it is possible to hypothesise that such a temporal constraint prevented assessment of multiple partners before the eventual choice. 
Further evidence of the prevention of sexual selection by temporal constraints in raptors has been produced by more than 15 years (1986-2000) of research on the Doñana (southwestern Spain) population of Spanish Imperial Eagle Aquila adalberti (FERRER 2001). During this period, $60 \%$ of breeding and floater individuals were equipped with radios. We recorded 20 independent mating events of marked individuals occurring within 8-24 hr of previous mate loss. In $60 \%$ of the observed events a new male occupied a vacancy in a territory in which there was a lone female, whereas in the remaining $40 \%$ of the events a female entered a territory occupied by a lone male as a new mate. These rapid changes always occurred in the highest quality territories. In low quality territories, also in the years in which the population reached its saturation threshold, changes occurred more slowly (e.g. over several months). The new pairs reproduced successfully after mating and pair bonds continued beyond the year of first mating.

In this time frame selection of the new mate was impossible because: (i) the vacancy was not filled by a floater that was regularly or intermittently present on the territory (even though some such individuals were older than the one which eventually filled the vacancy); and (ii) two prospecting individuals were never observed simultaneously at the same territory during a mating event.

One alternative possibility to the above is that sexual selection acts in more subtle and indirect ways. For example, in many avian species, males compete for access to territories or to be closest to a female (Ligon 1999). This could compensate for the reduction in the intensity of sexual selection that results from less time for female choice and, therefore, it could be hypothesised that sexual selection still acts indirectly as an increase in male-male competition when female choice is reduced. However, in the Spanish Imperial Eagle, the absence of fighting or territorial/sexual displays between male floaters (before they occupy a territory) near the breeding areas (FERRER 2001) suggests that male-male competition does not occur when female choice is constrained, preventing some males from being among the available males. In addition, during the above-cited mating events, we never observed two adult males fighting within a breeding territory to obtain a lone female.

In other raptor species (Kestrels, Ospreys Pandion haliaëtus and Peregrines), females look for mates that possess a good nest site and cannot afford to be too choosy, ignoring most other criteria (RAtcliffe 1980, Poole 1989, Village 1990). On the other hand, first-year Sparrowhawks Accipiter nisus previously excluded from nesting territories by dominant adults were promptly accepted when the adult disappeared (NEWTON 1986).

Because divorces exist in several taxonomic bird groups (BLACK 1996), the best strategy could be to accept the first new mate encountered to minimize the risk of territory loss. In addition, the rapid acquisition of a new mate will reduce or eliminate the potential costs associated with mate change, such as fighting rivals and searching for a new mate (ENs et al. 1996). In birds of prey, characterised by a protracted breeding cycle, taking a long time to select a mate may also prevent reproduction or delay laying for the current year. Late laying in these species is usually associated with low breeding success and low survival prospects for the offspring (NEWTON 1979).

\section{Acknowledgements}

Vincenzo Penteriani was supported by a European Community Marie Curie Fellowship: the author is solely responsible for information communicated and the European Commission is not responsible for any view or resulted expressed.

\section{References}

Andersson M. 1994. Sexual selection. Princeton: Princeton University Press.

BJöRKLUnd M. 1990. Mate choice is not important for female reproductive success in the Common Rosefinch (Carpodacus erythrinus). Auk 107: 35-44. 
Black J.M. 1996. Partnership in birds. Oxford: Oxford University Press.

BOWMAN R. \& BIRD D.M. 1987. Behavioral strategies of American kestrels during mate replacement. Behavioral Ecology and Sociobiology 20: 129-135.

Cunningham E.J.A. \& Birkhead T.R. 1998. Sex roles and sexual selection. Animal Behaviour 56: 1311-1321.

ECKert C.G. \& WeAtherheAd P.J. 1987. Competition for territories: is resource holding potential realized in red-winged blackbirds? Behavioral Ecology and Sociobiology 20: 369-375.

EmLen S.T. \& ORing L.W. 1977. Ecology, sexual selection, and the evolution of mating systems. Science 197: 215-223.

Ens B.J., Choudhury S. \& Black J.M. 1996. Mate fidelity and divorce in monogamous birds, pp. 344-395. In: Black J.M., Edit. Partnership in birds. Oxford: Oxford University Press.

Ferrer M. 2001. The Spanish Imperial Eagle. Madrid: Lynx Editions.

Ferrer M. \& Penteriani V. 2003. A process of pair formation leading to assortative mating: passive age-assortative mating by habitat heterogeneity. Animal Behaviour 66: 137-143.

GiBson R.M. \& LANGEN T.A. 1996. How do animals choose their mates? Trends in Ecology \& Evolution 11: 468-470.

Gontard-DaneK M.-C. \& Møller A.P. 1999. The strength of sexual selection: a meta-analysis of bird studies. Behavioral Ecology 10: 476-486.

Hubbell S.P. \& JohnSON L.K. 1987. Environmental variance in lifetime reproductive success, mate choice, and sexual selection. The American Naturalist 130: 91-112.

JAnetos A.C. 1980. Strategies of female mate choice: a theoretical analysis. Behavioral Ecology and Sociobiology 7: 107-112.

LigON J.D. 1999. The evolution of avian breeding systems. Oxford: Oxford University Press.

MARsh D.M., RAND A.S. \& RYAn M.J. 2000. Effects of inter-pond distance on the breeding ecology of tungara frogs. Oecologia 122: 505-513.

McLAin D.K. 1991. The r-K continuum and the relative effectiveness of sexual selection. Oikos 60: 263-265.

NefF B.D. 2001. Alternative reproductive tactics and sexual selection. Trends in Ecology \& Evolution 16: 669.

Newton I. 1979. Population ecology of raptors. London: $T \& A D$ Poyser.

Newton I. 1986. The Sparrowhawk. London: $T$ \& AD Poyser.

Newton I. \& Wyllie I. 1996. Monogamy in the Sparrowhawk, pp. 249-267. In: Black J.M., Edit. Partnership in birds. Oxford: Oxford University Press.

PARKer G.A. 1983. Mate quality and mating decision, pp. 141-166. In: Bateson P., Edit. Mate choice. Cambridge: Cambridge University Press.

Poole A.F. 1989. Ospreys. A natural and unnatural history. Cambridge: Cambridge University Press.

Ratcliffe D. 1980. The Peregrine Falcon. Vermillion: Buteo Books.

Rodenhouse N.L., Sherry T.W. \& Holmes R.T. 1997. Site-dependent regulation of population size: a new synthesis. Ecology 78: 2025-2042.

Rodenhouse N.L., Sherry T.W. \& Holmes R.T. 1999. Multiple mechanisms of population regulation: contributions of site dependence, crowding, and age structure, pp. 2939-2952. In: Adams N.J. \& Slow R.H., Edits. Proceedings 22 International Ornithological Congress. Durban: BirdLife South Africa.

Russel E. \& Rowley I. 1996. Partnerships in promiscuous Splendid Fairy-wrens, pp. 162-176. In: Black J.M., Edit. Partnership in birds. Oxford: Oxford University Press.

SEARCY W.A. 1979. Female choice of mates: a general model for birds and its application to red-winged blackbirds (Agelaius phoeniceus). The American Naturalist 114: 77-100.

Slagsvold T. \& Dale S. 1991. Mate choice models: can cost of searching and cost of courtship explain mating patterns of female Pied Flycatchers? Ornis Scandinavica 22: 319-326.

SUlLivan M.S. 1994. Mate choice as an information gathering process under time constraints: implication for behaviour and signal design. Animal Behaviour 47: 141-151.

Shutler D. \& WeAtherheAd P.J. 1991. Owner and floater red-winged blackbirds: determinants of status. Behavioral Ecology and Sociobiology 28: 235-241. 
Village A. 1990. The Kestrel. London: $T$ \& AD Poyser.

Winemiller K.O. 1992. Life-history strategies and the effectiveness of sexual selection. Oikos 63: 2.

V. Penteriani ${ }^{1}$, C. Alonso-Alvarez and M. Ferrer

Department of Applied Biology, Estación Biológica de Doñana (EBD), Consejo Superior de Investigaciones Científicas, Avda. de María Luisa s/n, Pabellón del Perú, Apdo. 1056, 41013 Sevilla, Spain.

${ }^{1}$ (Phone: + 3495 4232340; Fax: + 3495 4621125; E-mail: penteriani@ebd.csic.es). 